\title{
Metabolic resuscitation in pediatric sepsis: a narrative review
}

\author{
Luregn J. Schlapbach ${ }^{1,2} \wedge$, Claudio Flauzinho de Oliveira ${ }^{3}$, Sainath Raman $^{1}$, Daniela de Souza ${ }^{3}$ \\ ${ }^{1}$ Child Health Research Centre, The University of Queensland, and Paediatric Intensive Care Unit, Queensland Children's Hospital, Brisbane, \\ QLD, Australia; ${ }^{2}$ Department of Intensive Care and Neonatology, and Children's Research Center, University Children's Hospital Zurich, Zurich, \\ Switzerland; ${ }^{3}$ The Latin America Sepsis Institute, São Paulo, Brazil \\ Contributions: (I) Conception and design: LJ Schlapbach; (II) Administrative support: LJ Schlapbach; (III) Provision of study materials or patients: \\ None; (IV) Collection and assembly of data: LJ Schlapbach; (V) Data analysis and interpretation: LJ Schlapbach, D de Souza, CF de Oliveira, S \\ Raman; (VI) Manuscript writing: All authors; (VII) Final approval of manuscript: All authors. \\ Correspondence to: Prof. Luregn J. Schlapbach, MD, PhD. Head, Department of Intensive Care and Neonatology, University Children's Hospital \\ Zurich-Eleonore Foundation, Steinwiesstrasse 75, CH-8032 Zurich, Switzerland. Email: luregn.schlapbach@kispi.uzh.ch.
}

\begin{abstract}
Sepsis, defined as infection with associated organ dysfunction, accounts for most childhood deaths due to infection globally. Evidence for the optimal support of children with septic shock refractory to the initial sepsis management bundle remains minimal. There is an urgent need for more effective interventions. Administration of hydrocortisone in children with septic shock might fasten shock resolution, and has been shown to dampen the systemic host immune response, augment adrenergic effects, and support the stress response. Ascorbic acid (vitamin C) is one of the most powerful naturally occurring antioxidants and has beneficial effects on multiple pathways which are severely deranged during septic shock. A regimen combining hydrocortisone, ascorbic acid, and thiamine termed "metabolic resuscitation" or "HAT therapy" has been tested in large trials in critically ill adults with sepsis with conflicting results. Available information on intravenous ascorbic acid indicates an excellent safety profile even at very high doses both in adults and children. Given the pharmacological properties and beneficial effects shown both in vitro and in animal studies, and its safety profile, ascorbic acid either as a single therapy or as part of HAT treatment represents a promising candidate for future pediatric sepsis treatments. While pediatric age groups may be more susceptible to ascorbic acid deficiency during sepsis, there is a lack of high-quality trial data on HAT therapy in this age group. A single centre retrospective study identified potential for mortality benefit in children with septic shock, and the results from a randomized controlled pilot trial are being awaited. It is imperative for pediatric research on ascorbic acid and HAT in children with sepsis to critically investigate key questions related to pharmacology, dosing, timing, feasibility, safety, effects on short- and long-term outcomes, and generalisability in view of the global burden of sepsis.
\end{abstract}

Keywords: Ascorbic acid; hydrocortisone; child; septic shock; thiamine

Submitted Jan 04, 2021. Accepted for publication May 27, 2021.

doi: $10.21037 / \mathrm{tp}-21-1$

View this article at: http://dx.doi.org/10.21037/tp-21-1

\section{Background: the quest for new adjunctive sepsis therapies}

In 2017, an estimated 3 million neonates, children and adolescents succumbed to sepsis globally, and as many as
25 million suffered from sepsis (1). Sepsis, more recently defined as infection with associated organ dysfunction (2), thus accounts for most childhood deaths due to infection $(3,4)$. Subsequent to the resolution by the United Nations

^ ORCID: 0000-0003-2281-2598. 
World Health Assembly on sepsis $(5,6)$, there is an increased emphasis on stakeholders in child health, research, and policy making to develop better strategies addressing the health and economic burden due to pediatric sepsis $(4,7,8)$. The challenges to achieve improved outcomes for children with sepsis include availability of preventive measures such as vaccinations, obstacles to structured education and implementation of systematic quality improvement programs, but as well an urgent need for more effective interventions once sepsis is manifest (9). Even in wellresourced settings, sepsis accounts for or is contributing to approximately one in four deaths in Pediatric Intensive Care Units (PICUs) (10-12). Beyond the toll on mortality, survivors of pediatric sepsis and multi-organ dysfunction frequently develop long-term sequelae. This impacts on the functional performance and quality of life of survivors, imposing further burden to families (13).

While observational evidence supports the delivery of an initial sepsis treatment bundle in children $(14,15)$, overall outcomes and survival rates for pediatric sepsis have not sufficiently improved over the past decade (16). Importantly, there has been a paucity of high-quality randomized studies on new interventions in pediatric sepsis since the completion of the activated protein $\mathrm{C}$ trial (17). In particular, evidence for the optimal support of children with sepsis or septic shock refractory to the initial sepsis bundle remains minimal, which is in striking contrast to the high mortality observed in this group (18). Septic shock in children commonly presents with overwhelming speed, and the majority of deaths occur within the first 48 hours of presentation (19-22). At a global scale, there is thus a need for pragmatic, safe, and economically viable interventions which can be administered rapidly to children unresponsive to initial sepsis management.

\section{The concept of metabolic resuscitation in sepsis}

Unlike many other mammalian species, humans are unable to regenerate ascorbic acid. Adult patients with sepsis are often found to have extremely low ascorbic acid levels, as seen otherwise during scurvy (23). Thiamine deficiency is associated with high lactate and an increased risk of death (24). The properties of ascorbic acid and thiamine at cellular level fed the hypothesis that they may be of value as adjunctive therapy in sepsis-related organ dysfunction $(24,25)$. The potential for ascorbic acid and thiamine to work synergistically with hydrocortisone to support the host response during sepsis has led to a treatment protocol using hydrocortisone (50 $\mathrm{mg}$ per dose $\mathrm{q} 6 \mathrm{~h}$ ), ascorbic acid $(1.5 \mathrm{~g} \mathrm{q} 6 \mathrm{~h})$ and thiamine $(200 \mathrm{mg} \mathrm{q} 12 \mathrm{~h})$ in critically ill adult patients with sepsis (26). This regimen, also termed "metabolic resuscitation" or "HAT therapy" (hydrocortisone, ascorbic acid, thiamine) has been shown to be effective in restoring serum ascorbic acid levels (27). A single center study from the United States investigated the impact of applying this metabolic resuscitation regimen on mortality in adults with septic shock (28). The beforeafter study design used propensity matching and compared 47 patients with matched controls who had comparable baseline characteristics. The hospital mortality in the control group was $40.4 \%$ (19 of 47 ), compared to $8.5 \%$ ( 4 of 47 ) in the treatment group $(\mathrm{P}<0.001)$, resulting in an adjusted odds ratio for mortality of 0.13 associated with treatment ( $95 \%$ CI: 0.04 to $0.48, \mathrm{P}=0.002$ ). The study observed rapid improvement in several severity measures such as vasopressor requirement, Sequential Organ Failure Assessment (SOFA) scores, and lactate, indicating faster reversal of septic shock. These promising results have led to some ICUs adopting metabolic resuscitation as practice (29). Before reviewing clinical trial data on HAT, we will first discuss the rationale, safety and efficacy data on HAT components.

\section{Hydrocortisone in sepsis}

Steroids exert multiple potentially beneficial effects in septic shock, including dampening of the systemic host immune response, augmentation of adrenergic effects, and supporting the stress response (30). At the same time glucocorticoid therapy may be associated with side effects such as hyperglycaemia, hypertension, critical illness neuropathy, and, possibly, increased risk for hospitalacquired infections $(31,32)$. Several large randomizedcontrolled trials in adult patients treated in ICU with septic shock have consistently demonstrated faster reversal of septic shock using treatment with hydrocortisone for at least 72 hours, and a good safety profile (adverse events associated with hydrocortisoneaffected only $1.1 \%$ of the trial participants) (33-35). Despite the effect on blood pressure and shock reversal, controversy in relation to a mortality benefit of hydrocortisone persists. Adult sepsis guidelines currently recommend clinicians to consider intravenous hydrocortisone in patients in septic shock who are not responsive to fluid and moderate- to high-dose vasopressor therapy $(31,32,36)$. While the previous pediatric Surviving Sepsis Campaign (SSC) recommendations 
suggested initiating hydrocortisone if a child is at risk of adrenal insufficiency (37), the use of hydrocortisone in fluid refractory shock remains very common in pediatric age groups (38-40). The recent 2020 pediatric SSC guidelines do not recommend the use of hydrocortisone in fluidand-inotrope-responsive septic shock. They explicitly state that the benefit of hydrocortisone in paediatric septic shock remains to be determined (14). A large randomizedcontrolled trial in children comparing hydrocortisone in children with septic shock treated with inotropes versus placebo is currently underway (Stress Hydrocortisone In Pediatric Septic Shock; SHIPSS; ClinicalTrials.gov Identifier: NCT03401398).

\section{Thiamine in sepsis}

The interest in thiamine (vitamin B1) as an adjunct in sepsis therapy stems from its role as cofactor for vital steps in the energy metabolism, such as pyruvate dehydrogenasedependent metabolism of pyruvate to produce acetyl-CoA, and other key enzymes. Severe hypovitaminosis can manifest as Beriberi disease with cardiovascular failure, neurological symptoms, and lactic acidosis, which is attributed to failure of oxygen utilization. Thiamine deficiency has been reported in a number of pediatric critical illness states, such as diabetic ketoacidosis (41). Thiamine deficiency is common in adult and pediatric septic patients (42).

Different doses of thiamine treatment have been reported. Thiamine in general has an excellent safety profile, and adverse events are exceedingly rare (43). Wald et al. used $4 \mathrm{mg} / \mathrm{kg} / \mathrm{d}$ (maximum $200 \mathrm{mg} / \mathrm{dose}$, not stating the number of doses per day) for a duration of four days in children with septic shock and did not observe adverse effects (44). Weiss et al. retrospectively reviewed children admitted to a single PICU with septic shock who had received intravenous thiamine therapy over a sevenyear study period (42). Their study identified 6 patients and the according thiamine dosing ranged from 1 to $5 \mathrm{mg} / \mathrm{kg} / \mathrm{d}$ (administered $\mathrm{q} 24 \mathrm{~h}$ or $\mathrm{q} 12 \mathrm{~h}$ ), with a median duration of 9 days (range 8 to 30 days). Again no side effects were observed. Although lactate levels dropped rapidly in the children treated with intravenous thiamine, the decrease of lactate and of markers of organ dysfunction and shock was similar to matched children not treated with thiamine. In other metabolic diseases, even several fold higher doses of thiamine have been used (45).

In adults with sepsis, observational studies indicate potential benefit with intravenous thiamine therapy: a matched retrospective study of 123 patients receiving thiamine observed higher lactate clearance, and lower 28-day mortality (46). A randomized-controlled trial on thiamine, administered at $200 \mathrm{mg}$ intravenously q $12 \mathrm{~h}$ for up to 7 days in 88 adults with septic shock observed a decrease in lactate from baseline to 24 hours, but did not result in different primary or secondary outcomes compared to placebo (24).

\section{Insights into mechanisms of ascorbic acid in sepsis based on pre-clinical studies}

Sepsis-associated organ dysfunction and cellular death occur through ischemia as a result of impaired microcirculation during shock, direct pathogen-related local tissue damage, and complex interrelated processes leading to compromised cellular and mitochondrial function $(47,48)$. Ascorbic acid (Vitamin C) is one of the most powerful naturally occurring antioxidants and has effects on multiple pathways that are severely deranged during septic shock (25): This includes the neutralization of reactive oxygen species and the restoration of anti-oxidant molecules, activation of NFkappaB and mitigation of pro-inflammatory cytokines (49). In addition, ascorbic acid can restore $\mathrm{Fe}++$ and $\mathrm{Cu}++$ concentrations, and reduce glucocorticoid receptor oxidation thereby increasing glucocorticoid responsiveness. In vitro and animal data suggest that acorbic acid may protect the capillary endothelium from endotoxinrelated damage in the lungs and other organs (50). In an ovine model of gram-negative sepsis induced by Eschericia coli infusion, a very high dose of intravenous ascorbic acid $(0.5 \mathrm{~g} / \mathrm{kg}$ loading followed by $0.5 \mathrm{~g} / \mathrm{kg} / \mathrm{hr}$ for 6.5 hours $)$ led to improved cardiac output, blood pressure and renal perfusion, reduced fever and lower inotrope requirement, and restored urine output and hyperlactataemia (51). These findings suggest that ascorbic acid is a promising candidate to reverse the pathophysiology and organ dysfunction associated with sepsis warranting human trials (52).

\section{Safety of high-dose ascorbic acid}

The available information on intravenous ascorbic acid indicates an excellent safety profile. A systematic review of studies in adult patients reporting on harm related to high dose intravenous ascorbic acid (defined as $\geq 6,000 \mathrm{mg} / \mathrm{d}$, $\geq 75 \mathrm{mg} / \mathrm{kg} / \mathrm{d}$, or $\geq 3,000 \mathrm{mg} / \mathrm{m}^{2} / \mathrm{d}$ ) identified 74 eligible studies on a total of 2,801 participants (53). The median dose of ascorbic acid was $22,500 \mathrm{mg} / \mathrm{d}$ (IQR 
$8.25-63.75 \mathrm{~g} / \mathrm{d}$ ), which equals to $450 \mathrm{mg} / \mathrm{kg} / \mathrm{d}$ for a $50 \mathrm{~kg}$ adult. A total of 2,310 of these patients received ascorbic acid in nine double-blind RCTs. The adverse event rate in patients treated with ascorbic acid was very low $(<1$ per 100 patients) and was comparable to controls. Adverse events likely related to high dose ascorbic acid included oxalate nephropathy $(\mathrm{n}=5)$, hypernatremia $(\mathrm{n}=5)$, hemolysis in patients with glucose-6-phosphate dehydrogenase deficiency $(\mathrm{n}=3)$, glucometer errors $(\mathrm{n}=2)$, and kidney stones $(n=1)$. None of the likely ascorbic acid-related side effects was considered life-threatening. These findings indicate that intravenous high dose ascorbic acid therapy has a very good safety profile and adverse events seem not be more harmful compared to placebo in RCTs. A systematic review of the literature on potential harm associated to high dose ascorbic acid treatment in neonatal and pediatric age groups identified twelve studies reporting on a total of 855 patients, of which 194 received high-dose ascorbic acid (54). Four of these studies were double-blind RCTs. The median ascorbic acid dose was $260 \mathrm{mg} / \mathrm{kg} /$ day and ranged from 100 to $1,500 \mathrm{mg} / \mathrm{kg} /$ day. Similar to the systematic review on adult patients, the safety related to high dose ascorbic acid in children and neonates was very high with no adverse event associated with ascorbic acid reported (55-60).

\section{Clinical studies on ascorbic acid and HAT therapy in adults with sepsis (Table 1)}

A recent systematic review on metabolic resuscitation identified nine registered RCTs on variations of metabolic resuscitation in adults with septic shock testing the superiority of this approach compared to standard care (25). The CITRIS-ALI multicenter RCT in adults with sepsis and acute lung injury compared ascorbic acid to placebo. The study reported a mortality benefit associated with the intervention, while other outcomes were similar (mortality $46.3 \%$ placebo vs. $29.8 \%$ intervention, $\mathrm{P}=0.03$ ) (61). In Australia and New Zealand, the open label VITAMINS trial enrolled 216 adults with septic shock. There was no difference in mortality between the intervention and control arm $(22.6 \%$ vs. $20.5 \%, \mathrm{P}=0.69)(62,63)$. The double blind ORANGES trial randomized 137 patients and observed faster recovery of shock in the intervention arm (64). Of note, the study protocol allowed the use of open-label corticosteroids in the control (placebo) arm. Three further recent trials in critically ill adults with septic shock have been published, all of which did not show a mortality benefit with ascorbic acid. The ACTS

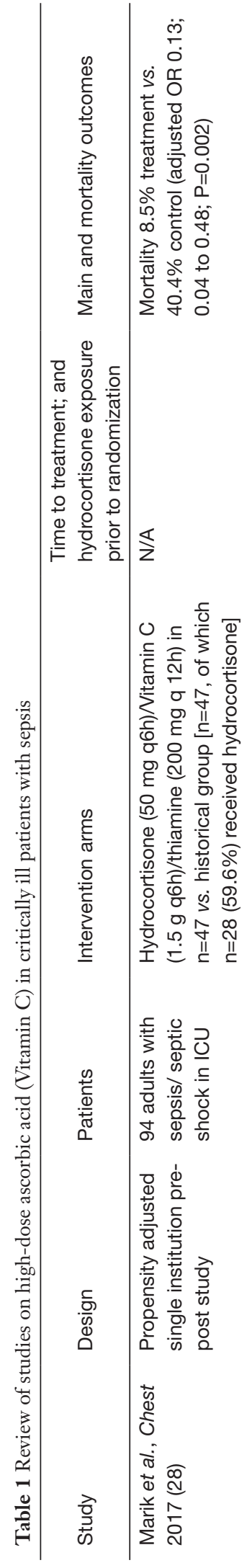

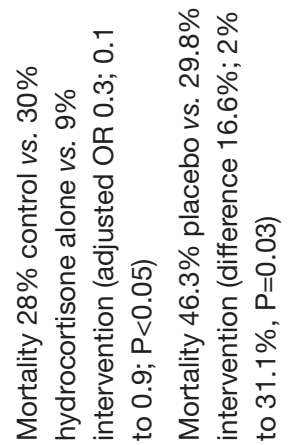

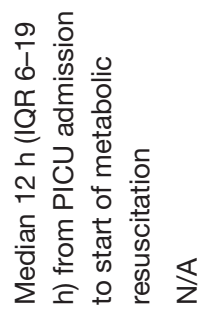

$\$$

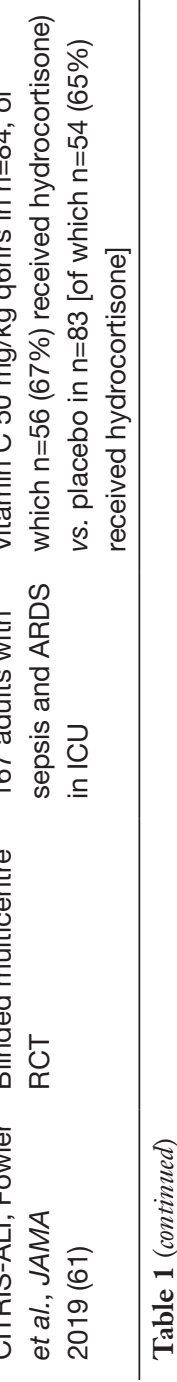




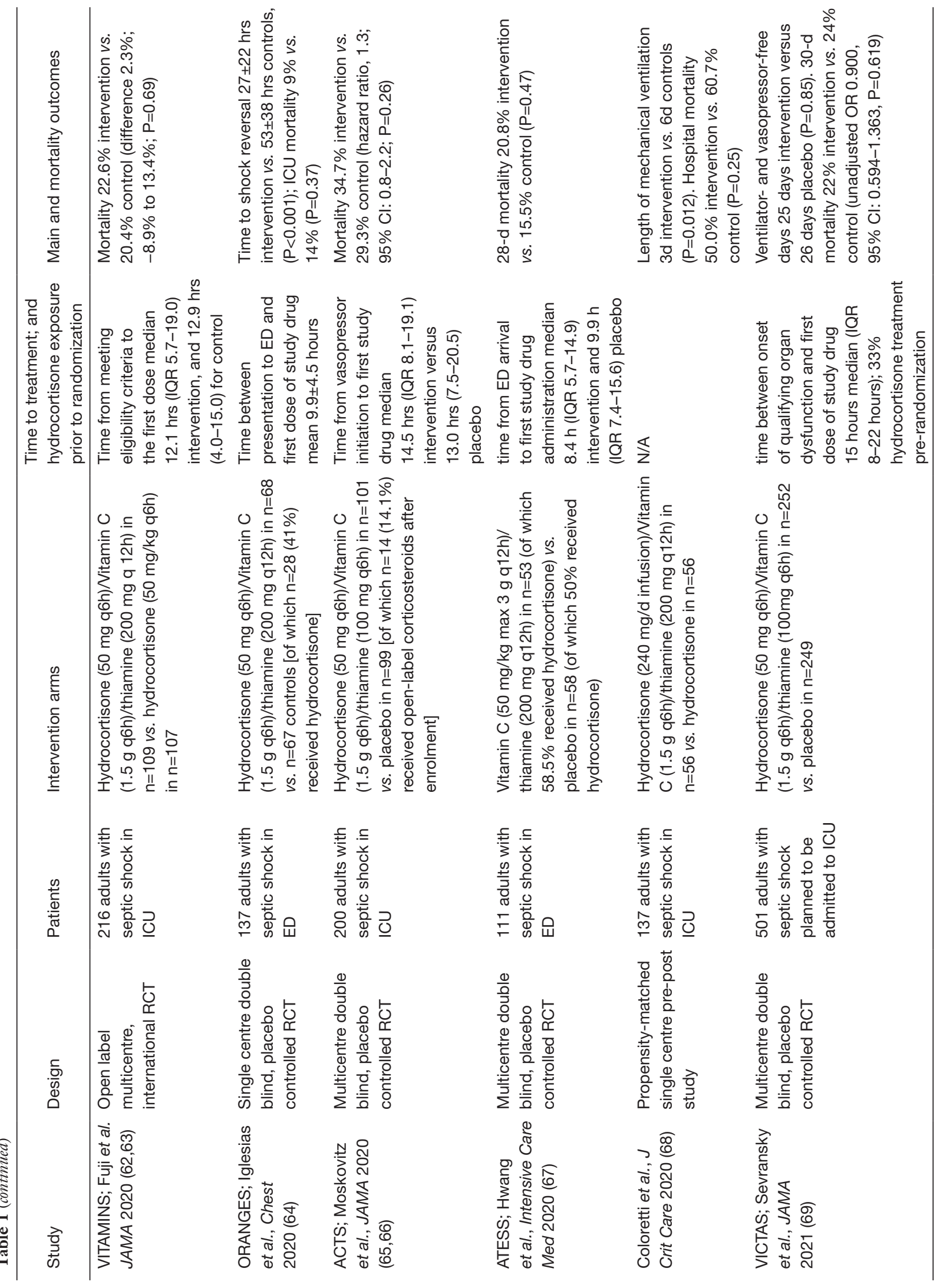


trial observed a higher survival free of shock (median difference 1 day, $\mathrm{P}=0.02$ ) in the 101 patients randomized to HAT compared to placebo, while other primary and secondary outcomes were not different $(65,66)$. The ATESS trial used a slightly higher ascorbic acid dose $(50 \mathrm{mg} / \mathrm{kg}$, max. $3 \mathrm{~g}$ ) and compared ascorbic acid and thiamine with placebo in 111 patients, but did not find significant outcome differences (67). A further single center propensitymatched study observed a shorter duration of ventilation in adults with sepsis receiving HAT therapy compared to hydrocortisone alone (68). The VICTAS trial utilized an adaptive design and was terminated after recruitment of 501 participants as funding was withheld by the main founder, despite interim analyses not having reached neither futility nor superiority thresholds (69-71). The authors calculated a $30.7 \%$ probability that full extension of the trial to the originally designed 2,000 participants may show efficacy of HAT on the primary outcome of ventilator- and vasopressor-free days.

Importantly, direct comparison of study findings is hampered by differences between the studies in relation to the type of patients enrolled, time to enrolment, intervention (ascorbic acid alone or HAT therapy), dosing of ascorbic acid and thiamine, use of hydrocortisone in the control arm, treatment with hydrocortisone prior to randomization, and blinding.

\section{Pediatric studies on ascorbic acid and HAT resuscitation-the RESPOND PICU study}

In critically ill children, decreases in serum ascorbic acid levels have been demonstrated and seem to be related to the degree of oxidative stress (72). Children could be more susceptible to ascorbic acid deficiency during sepsis due to factors such as chronic malnutrition, a high metabolic rate, and complex congenital conditions and comorbidities. Extrapolation of adult HAT trial results on children is therefore challenging, indicating a need for pediatric data. To date, only one study on metabolic resuscitation has been published (Table 1). This propensity-matched retrospective single center cohort study on 557 children with septic shock reported good safety of metabolic resuscitation in 43 children with septic shock (44). In adjusted analyses, HAT therapy was associated with decreased 30- and 90-day mortality $(\mathrm{P}<0.05)$ compared to hydrocortisone alone, and compared to standard care without hydrocortisone.

A search of trial registries revealed one registered RCT in pediatric age groups on metabolic resuscitation in septic shock (ACTRN12619000829112). The Resuscitation in Paediatric Sepsis Using Metabolic ResuscitationA Randomized Controlled Pilot Study in the Paediatric Intensive Care Unit (RESPOND PICU) trial led by the Paediatric Study Group of the Australian and New Zealand Intensive Care Society (ANZICS PSG) is recruiting 60 children admitted to PICU with septic shock treated with inotropes for at least two hours (73). This open label pilot study is expected to yield feasibility and safety data on metabolic resuscitation in critically ill children and will report on short- and long-term outcomes.

\section{Implications for future research}

In conclusion, the available evidence for high dose ascorbic acid and metabolic resuscitation indicates an excellent safety profile, but does not support a benefit of standard "high dose" vitamin c therapy in adults. Importantly, ascorbic acid is widely available and can be produced and purchased in healthcare settings around the world at relatively low cost. Given the pharmacological properties and beneficial effects shown in both in vitro and animal studies on sepsisrelated mechanisms detrimental to the host, ascorbic acid either as a single therapy or as part of HAT treatment remains a potential candidate for future pediatric sepsis treatments. However, in the history on sepsis research, the quest for magic bullets or one-size-fits-all approaches has failed too often. Pediatric intensivists and researchers should embrace lessons learnt in adults following the rapid uptake of HAT outside trials: Subsequent to low quality data and possibly augmented by social media, a change of practice in many institutions ensued despite the initial absence of high quality data (74), and despite several high quality RCTs subsequently not demonstrating clear benefit. By consequence, it is imperative for pediatric research to address key questions related to pharmacology, dosing, timing, feasibility, safety, and effects on short- and longterm outcomes of ascorbic acid and HAT in children with sepsis (Table 2). In the near future, we may witness the availability of personalized treatment options such as transcriptomics-based identification of sepsis phenotypes which carry the potential to magnify benefit to risk ratios in highly selected populations $(39,75,76)$. Finally, given substantial differences in epidemiology, host phenotype, and ICU resourcing (77), future studies in the field should seek to incorporate global trial sites which have not been 
Table 2 Gaps in knowledge and priorities for future research on hydrocortisone, ascorbic acid, and thiamine (HAT) therapy in pediatric sepsis

\begin{tabular}{|c|c|}
\hline Research questions & Considerations \\
\hline \multirow{3}{*}{$\begin{array}{l}\text { Optimal dosing and duration of ascorbic acid } \\
\text { therapy }\end{array}$} & Optimal dosing of high-dose ascorbic therapy \\
\hline & Duration \\
\hline & $\begin{array}{l}\text { Timing of administration (upon diagnosis of shock, upon initiation of inotropes, when } \\
\text { inotrope-refractory shock is diagnosed etc.) }\end{array}$ \\
\hline \multirow{3}{*}{ Optimal dosing and duration of thiamine therapy } & Duration \\
\hline & Timing of administration \\
\hline & Single therapy with thiamine versus combined therapy/HAT \\
\hline \multirow{3}{*}{$\begin{array}{l}\text { Identification of phenotypes more likely to benefit } \\
\text { from HAT }\end{array}$} & Ascorbic acid serum levels to guide therapy \\
\hline & Mitochondrial assays to guide thiamine therapy \\
\hline & Host immune monitoring to guide hydrocortisone therapy \\
\hline \multirow[t]{3}{*}{ Safety } & Safety of mega-dose and high-dose ascorbic acid \\
\hline & Safety of high-dose thiamine \\
\hline & Safety of HAT compared to standard care \\
\hline \multirow[t]{3}{*}{ Efficacy } & Impact of HAT therapy, or of its components, on \\
\hline & Survival free of organ support \\
\hline & Survival free of PICU \\
\hline \multirow{4}{*}{$\begin{array}{l}\text { Interventional trials investigating the effect of HAT } \\
\text { and HAT components (blinded or open label) }\end{array}$} & HAT versus standard care \\
\hline & HAT versus hydrocortisone alone versus standard care \\
\hline & Ascorbic acid alone versus standard care \\
\hline & Thiamine alone versus standard care \\
\hline \multirow{2}{*}{$\begin{array}{l}\text { Generalisability and considerations prior to } \\
\text { implementation }\end{array}$} & Cost effectiveness \\
\hline & $\begin{array}{l}\text { Impact of HAT or HAT components on long-term outcomes such as quality of life or } \\
\text { functional status }\end{array}$ \\
\hline
\end{tabular}


commonly represented in clinical trials.

\section{Acknowledgments}

Funding: LJS was supported by a National Health and Medical Research Council (NHMRC) Practitioner Fellowship and by the Children's Hospital Foundation, Australia.

\section{Footnote}

Provenance and Peer Review: This article was commissioned by the Guest Editors (Jan Hau Lee, Vijay Srinivasan, and Debbie Long) for the series "Pediatric Critical Care" published in Translational Pediatrics. The article has undergone external peer review.

Peer Review File: Available at http://dx.doi.org/10.21037/tp-21-1

Conflicts of Interest: All authors have completed the ICMJE uniform disclosure form (available at http://dx.doi. org/10.21037/tp-21-1). The series "Pediatric Critical Care" was commissioned by the editorial office without any funding or sponsorship. The authors have no other conflicts of interest to declare.

Ethical Statement: The authors are accountable for all aspects of the work in ensuring that questions related to the accuracy or integrity of any part of the work are appropriately investigated and resolved.

Open Access Statement: This is an Open Access article distributed in accordance with the Creative Commons Attribution-NonCommercial-NoDerivs 4.0 International License (CC BY-NC-ND 4.0), which permits the noncommercial replication and distribution of the article with the strict proviso that no changes or edits are made and the original work is properly cited (including links to both the formal publication through the relevant DOI and the license). See: https://creativecommons.org/licenses/by-ncnd/4.0/.

\section{References}

1. Rudd KE, Johnson SC, Agesa KM, et al. Global, regional, and national sepsis incidence and mortality, 1990-2017: analysis for the Global Burden of Disease Study. Lancet 2020;395:200-11.
2. Schlapbach LJ, Kissoon N. Defining Pediatric Sepsis. JAMA Pediatr 2018;172:312-4.

3. Liu L, Oza S, Hogan D, et al. Global, regional, and national causes of child mortality in 2000-13, with projections to inform post-2015 priorities: an updated systematic analysis. Lancet 2015;385:430-40.

4. Kissoon N, Uyeki TM. Sepsis and the Global Burden of Disease in Children. JAMA Pediatr 2016;170:107-8.

5. Reinhart K, Daniels R, Kissoon N, et al. Recognizing Sepsis as a Global Health Priority - A WHO Resolution. N Engl J Med 2017;377:414-7.

6. Schlapbach LJ, Kissoon N, Alhawsawi A, et al. World Sepsis Day: a global agenda to target a leading cause of morbidity and mortality. Am J Physiol Lung Cell Mol Physiol 2020;319:L518-22.

7. Fleischmann C, Scherag A, Adhikari NK, et al. Assessment of Global Incidence and Mortality of Hospital-treated Sepsis. Current Estimates and Limitations. Am J Respir Crit Care Med 2016;193:259-72.

8. Schlapbach LJ, Thompson K, Finfer SR. The WHO resolution on sepsis: what action is needed in Australia? Med J Aust 2019;211:395-7.e1.

9. Schlapbach LJ. Paediatric sepsis. Curr Opin Infect Dis 2019;32:497-504.

10. Weiss SL, Fitzgerald JC, Pappachan J, et al. Global epidemiology of pediatric severe sepsis: the sepsis prevalence, outcomes, and therapies study. Am J Respir Crit Care Med 2015;191:1147-57.

11. Schlapbach LJ, Straney L, Alexander J, et al. Mortality related to invasive infections, sepsis, and septic shock in critically ill children in Australia and New Zealand, 200213: a multicentre retrospective cohort study. Lancet Infect Dis 2015;15:46-54.

12. Hartman ME, Linde-Zwirble WT, Angus DC, et al. Trends in the epidemiology of pediatric severe sepsis*. Pediatr Crit Care Med 2013;14:686-93.

13. Schlapbach LJ, Aebischer M, Adams M, et al. Impact of sepsis on neurodevelopmental outcome in a Swiss National Cohort of extremely premature infants. Pediatrics 2011;128:e348-57.

14. Weiss SL, Peters MJ, Alhazzani W, et al. Surviving sepsis campaign international guidelines for the management of septic shock and sepsis-associated organ dysfunction in children. Intensive Care Med 2020;46:10-67.

15. Evans IVR, Phillips GS, Alpern ER, et al. Association Between the New York Sepsis Care Mandate and In-Hospital Mortality for Pediatric Sepsis. JAMA 2018;320:358-67. 
16. Moynihan KM, Alexander PMA, Schlapbach LJ, et al. Epidemiology of childhood death in Australian and New Zealand intensive care units. Intensive Care Med 2019;45:1262-71.

17. Nadel S, Goldstein B, Williams MD, et al. Drotrecogin alfa (activated) in children with severe sepsis: a multicentre phase III randomised controlled trial. Lancet 2007;369:836-43.

18. Morin L, Ray S, Wilson C, et al. Refractory septic shock in children: a European Society of Paediatric and Neonatal Intensive Care definition. Intensive Care Med 2016;42:1948-57.

19. Agyeman PKA, Schlapbach LJ, Giannoni E, et al. Epidemiology of Blood Culture-proven Bacterial Sepsis in Children in Switzerland - a Prospective Populationbased Cohort Study. Lancet Child Adolesc Health 2017;1:124-33.

20. Cvetkovic M, Lutman D, Ramnarayan P, et al. Timing of death in children referred for intensive care with severe sepsis: implications for interventional studies. Pediatr Crit Care Med 2015;16:410-7.

21. Schlapbach LJ, MacLaren G, Festa M, et al. Prediction of pediatric sepsis mortality within $1 \mathrm{~h}$ of intensive care admission. Intensive Care Med 2017;43:1085-96.

22. Weiss SL, Balamuth F, Hensley J, et al. The Epidemiology of Hospital Death Following Pediatric Severe Sepsis: When, Why, and How Children With Sepsis Die. Pediatr Crit Care Med 2017;18:823-30.

23. Carr AC, Rosengrave PC, Bayer S, et al. Hypovitaminosis $\mathrm{C}$ and vitamin $\mathrm{C}$ deficiency in critically ill patients despite recommended enteral and parenteral intakes. Crit Care 2017;21:300.

24. Donnino MW, Andersen LW, Chase M, et al. Randomized, Double-Blind, Placebo-Controlled Trial of Thiamine as a Metabolic Resuscitator in Septic Shock: A Pilot Study. Crit Care Med 2016;44:360-7.

25. Moskowitz A, Andersen LW, Huang DT, et al. Ascorbic acid, corticosteroids, and thiamine in sepsis: a review of the biologic rationale and the present state of clinical evaluation. Crit Care 2018;22:283.

26. Marik PE. "Vitamin S" (Steroids) and Vitamin C for the Treatment of Severe Sepsis and Septic Shock! Crit Care Med 2016;44:1228-9.

27. Hudson EP, Collie JT, Fujii T, et al. Pharmacokinetic data support 6-hourly dosing of intravenous vitamin $\mathrm{C}$ to critically ill patients with septic shock. Crit Care Resusc 2019;21:236-42.

28. Marik PE, Khangoora V, Rivera R, et al. Hydrocortisone,
Vitamin C, and Thiamine for the Treatment of Severe Sepsis and Septic Shock: A Retrospective Before-After Study. Chest 2017;151:1229-38.

29. Kuhn SO, Meissner K, Mayes LM, et al. Vitamin C in sepsis. Curr Opin Anaesthesiol 2018;31:55-60.

30. Heming N, Sivanandamoorthy S, Meng P, et al. Immune Effects of Corticosteroids in Sepsis. Front Immunol 2018;9:1736.

31. Annane D, Pastores SM, Arlt W, et al. Critical illnessrelated corticosteroid insufficiency (CIRCI): a narrative review from a Multispecialty Task Force of the Society of Critical Care Medicine (SCCM) and the European Society of Intensive Care Medicine (ESICM). Intensive Care Med 2017;43:1781-92.

32. Annane D, Pastores SM, Rochwerg B, et al. Guidelines for the diagnosis and management of critical illness-related corticosteroid insufficiency (CIRCI) in critically ill patients (Part I): Society of Critical Care Medicine (SCCM) and European Society of Intensive Care Medicine (ESICM) 2017. Intensive Care Med 2017;43:1751-63.

33. Venkatesh B, Finfer S, Cohen J, et al. Adjunctive Glucocorticoid Therapy in Patients with Septic Shock. N Engl J Med 2018;378:797-808.

34. Annane D, Renault A, Brun-Buisson C, et al. Hydrocortisone plus Fludrocortisone for Adults with Septic Shock. N Engl J Med 2018;378:809-18.

35. Annane D, Sebille V, Charpentier C, et al. Effect of treatment with low doses of hydrocortisone and fludrocortisone on mortality in patients with septic shock. JAMA 2002;288:862-71.

36. Rhodes A, Evans LE, Alhazzani W, et al. Surviving Sepsis Campaign: International Guidelines for Management of Sepsis and Septic Shock: 2016. Intensive Care Med 2017;43:304-77.

37. Davis AL, Carcillo JA, Aneja RK, et al. American College of Critical Care Medicine Clinical Practice Parameters for Hemodynamic Support of Pediatric and Neonatal Septic Shock. Crit Care Med 2017;45:1061-93.

38. Wong HR, Atkinson SJ, Cvijanovich NZ, et al. Combining Prognostic and Predictive Enrichment Strategies to Identify Children With Septic Shock Responsive to Corticosteroids. Crit Care Med 2016;44:e1000-3.

39. Wong HR, Cvijanovich NZ, Anas N, et al. Developing a clinically feasible personalized medicine approach to pediatric septic shock. Am J Respir Crit Care Med 2015;191:309-15.

40. Menon K, McNally D, O’Hearn K, et al. A Randomized Controlled Trial of Corticosteroids in Pediatric Septic 
Shock: A Pilot Feasibility Study. Pediatr Crit Care Med 2017;18:505-12.

41. Rosner EA, Strezlecki KD, Clark JA, et al. Low thiamine levels in children with type 1 diabetes and diabetic ketoacidosis: a pilot study. Pediatr Crit Care Med 2015;16:114-8.

42. Weiss SL, Blowey B, Keele L, et al. Matched Retrospective Cohort Study of Thiamine to Treat Persistent Hyperlactatemia in Pediatric Septic Shock. Pediatr Crit Care Med 2019;20:e452-6.

43. Mills CA. Thiamine overdosage and toxicity. JAMA 1941;116:2101.

44. Wald EL, Sanchez-Pinto LN, Smith CM, et al. Hydrocortisone-Ascorbic Acid-Thiamine Use Associated with Lower Mortality in Pediatric Septic Shock. Am J Respir Crit Care Med 2020;201:863-7.

45. Park SW, Yi YY, Han JW, et al. Wernicke's encephalopathy in a child with high dose thiamine therapy. Korean J Pediatr 2014;57:496-9.

46. Woolum JA, Abner EL, Kelly A, et al. Effect of Thiamine Administration on Lactate Clearance and Mortality in Patients With Septic Shock. Crit Care Med 2018;46:1747-52.

47. Hotchkiss RS, Moldawer LL, Opal SM, et al. Sepsis and septic shock. Nat Rev Dis Primers 2016;2:16045.

48. Hotchkiss RS, Karl IE. The pathophysiology and treatment of sepsis. N Engl J Med 2003;348:138-50.

49. Sweeney TE, Perumal TM, Henao R, et al. A community approach to mortality prediction in sepsis via gene expression analysis. Nat Commun 2018;9:694.

50. Barabutis N, Khangoora V, Marik PE, et al. Hydrocortisone and Ascorbic Acid Synergistically Prevent and Repair Lipopolysaccharide-Induced Pulmonary Endothelial Barrier Dysfunction. Chest 2017;152:954-62.

51. Lankadeva YR, Peiris RM, Okazaki N, et al. Reversal of the Pathophysiological Responses to Gram-Negative Sepsis by Megadose Vitamin C. Crit Care Med 2021;49:e179-90.

52. Fujii T, Deane AM, Nair P. Metabolic support in sepsis: corticosteroids and vitamins: the why, the when, the how. Curr Opin Crit Care 2020;26:363-8.

53. Yanase F, Fujii T, Naorungroj T, et al. Harm of IV HighDose Vitamin C Therapy in Adult Patients: A Scoping Review. Crit Care Med 2020;48:e620-8.

54. Yanase F, Raman S, Naorungroj T, et al. Efficacy and Safety of Parenteral High Dose Vitamin C Therapy in Pediatric Patients: A Scoping Review. Pediatr Crit Care Med 2021. [Epub ahead of print].
55. Aly H, Abd-Rabboh L, El-Dib M, et al. Ascorbic acid combined with ibuprofen in hypoxic ischemic encephalopathy: a randomized controlled trial. J Perinatol 2009;29:438-43.

56. Bass WT, Malati N, Castle MC, et al. Evidence for the safety of ascorbic acid administration to the premature infant. Am J Perinatol 1998;15:133-40.

57. Jiao F, Guo X, Lin J, et al. A Randomized Trial of Ligustrazini Hydrochlorioi in the Treatment of Viral Encephalitis in Children. Journal of Nepal Paediatric Society 2010;30:119-22.

58. Mikirova N, Hunnunghake R, Scimeca RC, et al. HighDose Intravenous Vitamin C Treatment of a Child with Neurofibromatosis Type 1 and Optic Pathway Glioma: A Case Report. Am J Case Rep 2016;17:774-81.

59. Rino PB, Scolnik D, Fustinana A, et al. Ascorbic acid for the treatment of methemoglobinemia: the experience of a large tertiary care pediatric hospital. Am J Ther 2014;21:240-3.

60. Uslu S, Comert S. Transient neonatal methemoglobinemia caused by maternal pudendal anesthesia in delivery with prilocaine: report of two cases. Minerva Pediatr 2013;65:213-7.

61. Fowler AA, 3rd, Truwit JD, Hite RD, et al. Effect of Vitamin C Infusion on Organ Failure and Biomarkers of Inflammation and Vascular Injury in Patients With Sepsis and Severe Acute Respiratory Failure: The CITRIS-ALI Randomized Clinical Trial. JAMA 2019;322:1261-70.

62. Fujii T, Luethi N, Young PJ, et al. Effect of Vitamin C, Hydrocortisone, and Thiamine vs. Hydrocortisone Alone on Time Alive and Free of Vasopressor Support Among Patients With Septic Shock: The VITAMINS Randomized Clinical Trial. JAMA 2020;323:423-31.

63. Fujii T, Udy AA, Deane AM, et al. Vitamin C, Hydrocortisone and Thiamine in Patients with Septic Shock (VITAMINS) trial: study protocol and statistical analysis plan. Crit Care Resusc 2019;21:119-25.

64. Iglesias J, Vassallo AV, Patel VV, et al. Outcomes of Metabolic Resuscitation Using Ascorbic Acid, Thiamine, and Glucocorticoids in the Early Treatment of Sepsis: The ORANGES Trial. Chest 2020;158:164-73.

65. Moskowitz A, Huang DT, Hou PC, et al. Effect of Ascorbic Acid, Corticosteroids, and Thiamine on Organ Injury in Septic Shock: The ACTS Randomized Clinical Trial. JAMA 2020;324:642-50.

66. Moskowitz A, Yankama T, Andersen LW, et al. Ascorbic Acid, Corticosteroids and Thiamine in Sepsis (ACTS) protocol and statistical analysis plan: a prospective, 
multicentre, double-blind, randomised, placebo-controlled clinical trial. BMJ Open 2019;9:e034406.

67. Hwang SY, Ryoo SM, Park JE, et al. Combination therapy of vitamin $\mathrm{C}$ and thiamine for septic shock: a multi-centre, double-blinded randomized, controlled study. Intensive Care Med 2020;46:2015-25.

68. Coloretti I, Biagioni E, Venturelli S, et al. Adjunctive therapy with vitamin $\mathrm{c}$ and thiamine in patients treated with steroids for refractory septic shock: A propensity matched before-after, case-control study. J Crit Care 2020;59:37-41.

69. Sevransky JE, Rothman RE, Hager DN, et al. Effect of Vitamin C, Thiamine, and Hydrocortisone on Ventilator- and Vasopressor-Free Days in Patients With Sepsis: The VICTAS Randomized Clinical Trial. JAMA 2021;325:742-50.

70. Walter KL, Seymour CW. Hydrocortisone, Vitamin $\mathrm{C}$, and Thiamine for Treatment of Sepsis. JAMA 2021;325:730.

71. Bauchner H, Fontanarosa PB, Golub RM. Funding and DSMB Membership in the VICTAS Clinical Trial. JAMA

Cite this article as: Schlapbach LJ, de Oliveira CF, Raman S, de Souza D. Metabolic resuscitation in pediatric sepsis: a narrative review. Transl Pediatr 2021;10(10):2678-2688. doi: $10.21037 /$ tp-21-1
2021;325:751.

72. Valla FV, Bost M, Roche S, et al. Multiple Micronutrient Plasma Level Changes Are Related to Oxidative Stress Intensity in Critically Ill Children. Pediatr Crit Care Med 2018;19:e455-63.

73. Schlapbach LJ, Gibbons K, Ridolfi R, et al. Resuscitation in Paediatric Sepsis Using Metabolic ResuscitationA Randomized Controlled Pilot Study in the Paediatric Intensive Care Unit (RESPOND PICU): Study Protocol and Analysis Plan. Front Pediatr 2021;9:663435.

74. Brant EB, Angus DC. Is High-Dose Vitamin C Beneficial for Patients With Sepsis? JAMA 2019;322:1257-8.

75. Wong HR, Caldwell JT, Cvijanovich NZ, et al. Prospective clinical testing and experimental validation of the Pediatric Sepsis Biomarker Risk Model. Sci Transl Med 2019;11:eaax9000.

76. Wong HR. Intensive care medicine in 2050: precision medicine. Intensive Care Med 2017;43:1507-9.

77. Schlapbach LJ, Gelbart B, Festa M, et al. Global paediatric critical care research: mind the gaps. Intensive Care Med 2019;45:753-4. 